\title{
A QUESTÃO DO VALOR DO CLIMA
}

\author{
THE PROBLEM OF THE VALUE OF CLIMATE
}

UNA CUESTIÓN DEL VALOR DEL CLIMA

\author{
Aristeu Geovani de Oliveira - UEG - Itapuranga - Brasil \\ arigo@pop.com.br
}

\begin{abstract}
Resumo
Esta proposta teve como objetivo a busca de uma conceituação de valor do clima que dê conta de explicar um valor que não pode ser demonstrado pelo critério numérico. A quantificação aparece como uma maneira de referenciar a impossibilidade da expressão quantitativa do referido valor, visando um rompimento com a tradição teórica e metodológica da "representação" das qualidades herdadas de qualquer fenômeno geográfico. A metodologia deve ser compreendida aqui, como os procedimentos dessa busca conceitual, fundada numa perspectiva geográfica, cujo parâmetro está firmado na precipitação pluviométrica, enquanto variável climática preponderante na apreensão do valor do clima. A avaliação do conceito de valor associado ao fenômeno físico - clima - e com base na importância geográfica e social da variável precipitação, permitiu afirmar que o valor é, nesse sentido, uma qualidade atribuída à espacialidade do clima. Além disso, é a diferenciação geográfica o fator responsável pela definição do referido valor. Palavras-chave: Conceito. Valor. Clima.
\end{abstract}

\section{Abstract}

This proposal has as goal the search of one conception of the value of the climate that can explain a value that can't be demonstrated by numerical criterion. The qualification appear as a manner of reference of the impossibility of the quantitative expression of the referred value, aspiring a rupture with the theorical tradition of inherited qualities of any geographic phenomenon. The methodology must be comprehended here as the procedure of this conceptual search, founded in a geographic perspective which the indicator is firmed in the precipitation while the changeable climate preponderating in the apprehension of the climate's values. The evaluation of the values concept associated to the physic climate phenomenon and based in the social and geographic importance of the changeable precipitation, permitted to assert that the value is in the sense, a quality attributed to the climate spatiality. Besides, it is the geographic differentiation the responsible for the definition of the referred value.

Key words: Concept. Value. Climate.

\section{Resumen}

Esta propuesta tuvo como objetivo la búsqueda de una conceptuación de valor del clima que explique un valor que no se puede demostrar por criterios numéricos. La cuantificación aparece como una manera de referenciar la imposibilidad de la expresión cuantitativa del valor referido, con miras a un rompimiento con la tradición teórica y metodológica de la "representación" de las cualidades heredadas de cualquier fenómeno geográfico. La metodología debe ser comprendida aquí como los procedimientos de esta búsqueda conceptual, fundada en una perspectiva geográfica, cuyo parámetro está fijado en la precipitación pluviométrica como variable climática preponderante en la aprehensión del valor del clima. La evaluación del concepto de valor relacionado con el fenómeno físico - clima, y con base en la importancia geográfica y social de la variable precipitación, permitió afirmar que el valor es, en este sentido, una cualidad atribuida a la espaciosidad del clima. Además, es la diferenciación geográfica el factor responsable por la definición del referido valor.

Palabras clave: Concepto. Valor. Clima.

B.goiano.geogr, Goiânia, v. 29, n. 2, p. 101-111, jul./dez, 2009 


\section{Introdução}

O clima, enquanto um elemento natural constituído por um conjunto de parâmetros meteorológicos tais como temperatura, umidade do ar, ventos, precipitação, insolação, entre outros, funciona como um sistema dotado de relações complexas, e ao longo do tempo, imprime sua marca à superfície, contribuindo para a formação de diferentes paisagens, que ao longo dos anos, foram ocupadas por diferentes grupos sociais, que ali se estabeleceram em função de um ambiente propício às suas necessidades vitais. Nesses ambientes, desenvolveram os seus modelos produtivos que se adaptaram às condições oferecidas pelo meio e se constituíram nas diversas sociedade e, seguindo uma lógica evolutiva, chegaram a diferentes graus de desenvolvimento.

Assim, o elemento natural clima esteve presente em todas as fases de desenvolvimentos desses diferentes grupos sociais, e por isso, foi incorporado indiretamente ao processo produtivo, se tornando um "insumo da produção” uma vez que as ações desses grupos sempre buscaram desenvolver-se de forma a aproveitar as condições oferecidas pelo meio.

Desse modo, os sistemas produtivos sustentados nas atividades econômicas do setor primário, principalmente a agricultura, pecuária e as diversas formas de extrativismo vegetal e animal, são extremamente dependentes do sistema climático e estão constantemente sujeitas às ocorrências climáticas. Qualquer anomalia verificada pelo sistema clima, pode afetar, imediatamente, a produção e gerar uma reação em cadeia, impactando inclusive, na estabilidade da economia local.

A relação entre a sociedade e o sistema climático caracteriza um processo de entropia, uma vez que as ações antrópicas também podem interferir no meio influenciando a sua dinâmica. Essa realidade torna o clima um objeto de estudo da Geografia, constituindo, portanto, um vasto campo de análise por onde os diversos ramos da ciência geográfica debruça-se em busca da construção de um pensamento teórico e metodológico que possa contribuir para o entendimento da dinâmica climática, objetivando uma ocupação racional do espaço.

Assim, estudos que abordem a temática clima, através de seus vários atributos, são hoje norteadores das diversas discussões que se fazem frente ao atual momento na história do planeta Terra, onde o tema Aquecimento Global se tornou o mais novo paradigma posto para a Ciência, e sobretudo para a ciência Geográfica.

Contudo, ressalta-se que urge no mundo do pensamento geográfico, a elaboração de uma nova visão de análise, onde os velhos vícios pautados em 
uma interpretação, muitas das vezes errôneas, e positivistas do passado, sejam substituídos pelas novas possibilidades de uma revisão de paradigmas que possa conduzir à renovação dos métodos que venham a concretizar os novos caminhos a ser percorridos pela Geografia.

Neste contexto é que "Epistemologia e Geografia", artigo de Moraes (1985), é um convite aos geógrafos que desejam romper com a "tradição teórica” da Geografia, fundada no pensamento positivista. Seus argumentos reivindicam uma nova postura à ciência geográfica, no sentido de provocar a inquirição do real, diante da renovação crítica da Geografia.

Atesta o fundamento desta renovação nas “(...) novas opções quanto ao método de interpretação do real, (...)”. (MORAES, 1985, p. 76). Aposta em novas formas de elaboração do conhecimento, pelo estudo de "experiências teóricas”. Encoraja para a produção do "saber geográfico crítico” passando pelos seguintes aspectos: “(...) do equacionamento crítico do passado, o do aprendizado metodológico e do enriquecimento temático na compreensão do objeto.” (MORAES, 1985, p. 78).

Desse modo, o posicionamento crítico diante do discurso geográfico tradicional, aparece como um trabalho epistemológico emergente. A necessidade da busca de novas metodologias, e a busca do pensamento geográfico em autores/obras fora da perspectiva geográfica, mas que auxiliem os temas referentes à uma "Geografia da Sociedade", estão na base da construção da Geografia pela via epistemológica.

Esse pensamento conduz às necessidades próprias da constituição/ composição da Geografia, no âmbito dos diversos saberes científicos. No que concerne à temática, aqui proposta, tomamos como exemplo a discussão do meio físico e seus atributos onde é imprescindível a elaboração de uma "Geografia do Clima”, ideia defendida por Sant'Anna Neto (2001; 2004), para quem deve haver uma “(...) climatologia eminentemente humana e geográfica (...)".

A compreensão dessa Geografia não deve ser simplesmente como o faz a Climatologia Geográfica, pelo tripé "ritmo climático - ação antrópica - impacto ambiental”, mas por uma interpretação crítica da realidade, na perspectiva geográfica, que considere “(...) um entendimento dos fenômenos atmosféricos que responda às indagações e necessidades exigidas pela sociedade (...)" (SANT'ANNA NETO, 2001, p. 56).

Assim, para esse autor, deve-se questionar, inclusive, sobre a utilização do clima, através do conjunto de seus elementos, pelos diversos sistemas produtivos como um recurso com valor de uso, no processo capitalista de produção, em cada contexto histórico. A periodização e historicização, é ideia também defendida por Santos (1985). 
Trata-se de considerar a dimensão social nos estudos sobre o clima, incluindo os diversos grupos sociais e seus referidos aparatos tecnológicos de produção, sejam eles “arcaicos ou modernos”, o que remete à discussão sobre o valor do clima também fora da órbita puramente técnica e quantitativa. Este é o cerne da referência teórica aqui esboçada, qual seja, a do estabelecimento do valor do clima para cada grupo social e momento histórico em questão.

Nesse sentido, o objetivo deste ensaio é a elaboração de uma discussão que visa colocar em pauta o valor econômico do clima, neste caso, um "valor subjetivo", através da análise de seus diversos parâmetros. Em específico, tomou-se como objeto de análise a variável precipitação pluviométrica, enquanto elemento importante para o processo produtivo, e de ocorrência de forma temporalmente variada e irregular no espaço geográfico.

\section{A busca de uma metodologia para o "Valor do Clima"}

A interpretação do valor do clima não deve se dar a partir de modelos metodológicos, tampouco de classificações estabelecidas por critérios meramente matemáticos ou estatísticos, pois não se trata de demonstrar o caráter representativo de valores numéricos, em que pese a importância da quantificação ainda que para as interpretações subjetivas dos fenômenos encontrados na realidade.

Na proposta em tela, pretendeu-se mais apresentar uma breve discussão sobre o valor do clima, ainda que seja para a ideia do seu valor econômico, de modo a realçar a superação técnica da elaboração de um conceito que satisfaça, simplesmente, o significado do valor econômico obtido através de dados matemáticos. Para tanto, utilizou-se de dados primários de área plantada e produção de milho, correlacionadas ao volume de precipitação pluviométrica.

Com efeito, esta proposta prende-se mais à uma abstração, pela significação geográfica intrínseca à uma realidade ainda pouco debatida dentro do pensamento geográfico, sobretudo, no âmbito dos estudos do clima. Depreende-se ainda que estão nas variáveis do clima e na sua forma de ocorrência sobre a superfície da Terra, as condições de apreensão deste valor.

A precipitação pluviométrica, por ser a responsável pela entrada de recursos hídricos em determinada porção da superfície terrestre, foi tomada, aqui, como parâmetro fundamental, pelas condições empíricas que oferece, como componente fenomênica na apreensão diferencial do valor que 
pode se inferido ao clima quando se discute a sua importância no processo produtivo, principalmente os agrários.

As referências teóricas da problemática em tela fundamentam-se também no valor como elemento de significação geográfica em seu aspecto conceitual, conforme as reflexões de Saussure (2006, p. 141).

Como forma de referenciar a questão do conceito de valor dos elementos naturais, Santos (1985) discutiu os elementos do espaço em seu aspecto de significação conceitual privilegiando uma das diversas possibilidades de análise do espaço - como uma totalidade. Conforme Santos (1985) os elementos do espaço são: “(...) os homens, as firmas, as instituições, o chamado meio ecológico e as infra-estruturas.” (SANTOS, 1985, p. 6). Assim, afirmou que estes elementos possuem variações quantitativas e qualitativas, cujos valores mudam conforme a História. Entretanto, a base desses valores são suas qualidades, representadas, comumente, por quantidades, que devem ser consideradas posteriormente à apreensão das qualidades, o que justifica pelo fato da diferenciação do valor de cada elemento do espaço se dar de acordo com o lugar em que se encontra. (SANTOS, 1985, p. 10).

Neste caso, há uma "valorização específica" que deve ser considerada na análise da totalidade geográfica.

Já para Saussure (2006), os dois fatores que exprimem a existência do valor é a possibilidade de troca por outra quantidade, e a de comparação com um valor semelhante, dentro do mesmo sistema. (SAUSSURE, 2006, p. 134).

Nesse sentido, enquanto uma totalidade para apreensão, o valor consiste um signo cuja diferença faz a característica, o valor e a unidade. (p. 141). Tal assertiva, pode ser tomada como premissa para os estudos dos fenômenos climáticos, onde a discussão sobre o valor do clima esteja em questão.

Vê-se com isso que a discussão aqui presente, é um campo de possibilidades que, ao sabor das variáveis geográficas, deveriam constituir objeto de desejo dos geógrafos, na busca da construção de teorias que venham a dar conta de uma nova perspectiva de análise na ocupação do espaço geográfico pelos diversos grupos sociais.

\section{Os dados numéricos na representação do valor}

A expressão empírica desta temática tem como objeto de estudo as precipitações ocorridas no município de Jataí-GO, durante os anos de 1990 a 2004, e a partir da análise das médias pluviométricas (utilizando metodologia da Geografia Tradicional). 
O município de Jataí está localizado na microrregião denominada Sudoeste de Goiás, na divisão regional do IBGE (IBGE, 1990), distando 330 km de Goiânia, capital do estado de Goiás. Situa-se entre as coordenadas geográficas $17^{\circ} 16^{\prime}$ e $18^{\circ} 32^{\prime}$ de latitude sul e $51^{\circ} 12^{\prime}$ e $52^{\circ} 17^{\prime}$ de longitude oeste, com altitude variando entre 650 e $750 \mathrm{~m}$. O município possui uma área de $7.174,217$ km². Sua população total é de 81.972 hab., sendo 75.668 residentes na área urbana e apenas 6.304 habitando a zona rural (IBGE, 2007). A área do município era coberta por vegetação natural dos domínios do cerrado, que ao longo dos anos, foi sendo eliminada para dar lugar às atividades de agricultura e pecuária.

Para a elaboração da análise, tomou-se os dados da produção de milho no referido município, onde utilizando dos dados da expansão da área plantada e sua respectiva produção, realizou-se uma comparação com o volume das médias de precipitações, entre o ano de 1990 e 2004.

Quando observado apenas o volume médio anual das precipitações, obtidos a partir do volume de precipitações média mensal, o gráfico de precipitação do município (Gráfico 1) mostra que durante o período em estudo, houve pequenas variações na altura das médias, quando, em um ou outro ano, registrou-se diferentes volumes de precipitação, mas que não configuram em um primeiro olhar, alterações intensas no sistema pluviométrico local.

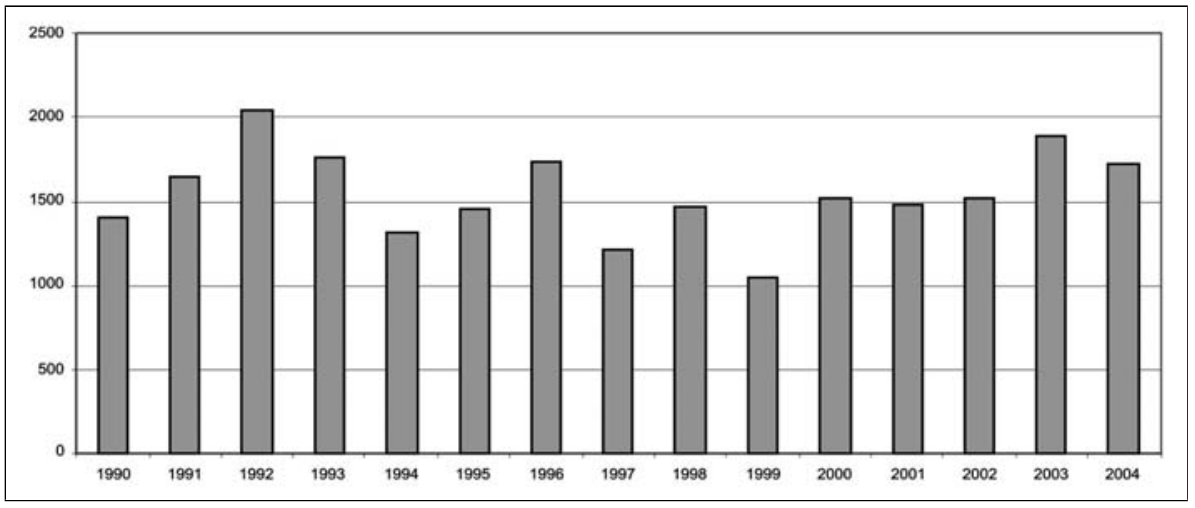

Gráfico 1: Jataí - Precipitação média anual, 1990-2004.

Fonte: http://hidroweb.ana.gov.br . Estação 18510004.

No entanto, é sabido que as médias nem sempre conseguem representar a realidade, uma vez que, na sua elaboração, são aplicadas metodologias que 
podem "mascarar" parte desta realidade. Prova disto, sabemos que o interior do Brasil é marcado por duas estações bem definidas, sendo um inverno seco e o verão chuvoso, e o gráfico das médias de precipitação, escondem este fato.

Quanto à relação desses volumes pluviométricos na produção, é uma outra incógnita, uma vez que não se pode discutir os dados volumétricos, sem levar em consideração a realidade específica de cada sistema produtivo e, dentro deste, as diferentes condições de cada produtor em particular.

Nesta perspectiva, a precipitação pluviométrica que é um parâmetro climático, não apresenta qualquer significado que possa levar a uma noção ou entendimento, mesmo que mínima, de um determinado valor (econômico/financeiro) que possa estar a ela relacionado.

Por outro lado, quando tomados os dados das médias pluviométricas e os correlacionados com os dados de produção de milho (Gráfico 2), no período em estudo, verifica-se a possibilidade de relação direta entre as alturas da precipitação e a quantidade produzida. Numa análise superficial, pode-se afirmar que a precipitação é um elemento que, "possivelmente", contribui para a variabilidade da produção. Enquanto as médias pluviométricas anuais variam, consideravelmente, ao longo dos anos, não indicando um estágio de regularidade, a linha que representa a produção indica uma tendência de aumento, com algumas oscilações que as vezes combinam com as variações da precipitação.

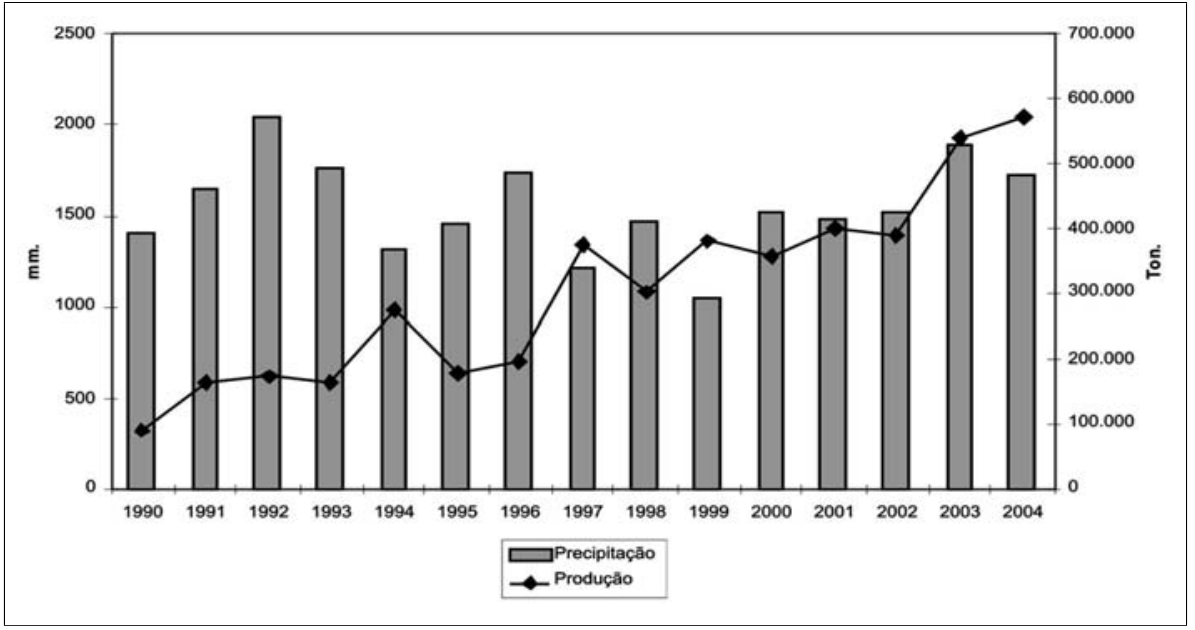

Gráfico 2: Jataí - Precipitação média anual (mm.) e produção de milho (ton.), 1990-2004. Fonte: http://hidroweb.ana.gov.br; http://www.sidra.ibge.gov.br. 
Considerando-se que o volume pluviométrico, em virtude da sua forma de ocorrência, pode alterar os resultados finais da produção, tem-se, por indução, uma primeira noção da existência de um valor, embora ainda não definido, da variável precipitação, ou seja, se esta variável pode afetar os resultados da produção, é claro que por consequência, afetará as demais fases pós-produção (comercialização e consumo), por exemplo.

No entanto, como nos Gráficos 1 e 2 tem-se apenas um conjunto de informações isoladas onde aparece somente as variáveis tempo, média pluviométrica e produção (neste caso, de milho), insuficientes na elaboração de uma análise maior, há desse modo a necessidade de informações complementares.

Por outro lado, quando adicionado uma nova variável à esta discussão, como a área plantada, amplia-se a possibilidade de realização de uma análise precisa, tornando mais próximo da realidade o significado da variável precipitação, que pode, agora, revelar se houve ou não, influência resultante da sua ocorrência.

Observando as curvas da área plantada e da produção (Gráfico 3), percebe-se que as duas variáveis apresentam uma ordem evolutiva muito próxima, uma vez que apenas no período entre os anos de 1999 e 2002 ocorre um distanciamento na tendência de crescimento das mesmas.

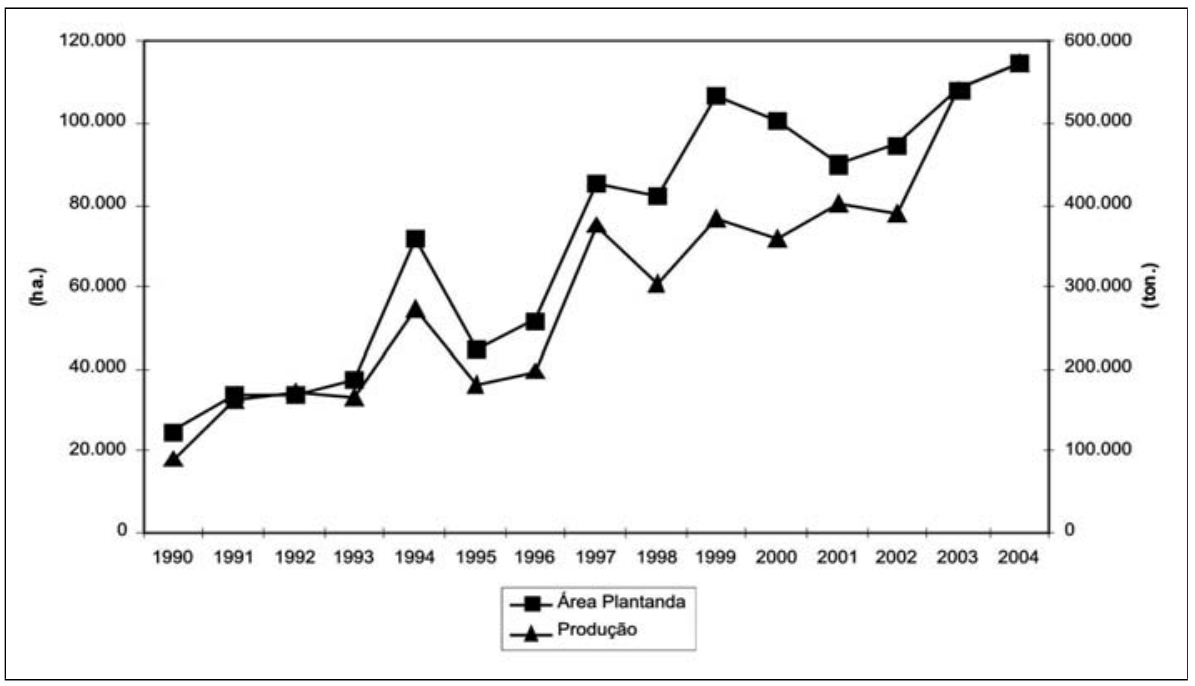

Gráfico 3: Jataí - Área plantada (ha.) e produção de milho (ton.), 1990-2004.

Fonte: http://www.sidra.ibge.gov.br. 
Contudo, a relação entre a área plantada e a produção (gráfico 3) não expressa claramente se houve esta participação direta da precipitação, observando-se que além desta variável, soma-se a ela, um conjunto de fatores que podem alterar a produtividade e devem ser considerados, como por exemplo, o melhoramento genético das sementes, o uso de fertilizantes e defensivos, e o aparato tecnológico entre outros.

Agora, quando tomado os dados brutos da área plantada e da produção (Quadro 1) observa-se que em alguns anos, ocorreu uma variação significativa entre estas. Do ano de 1992 para 1993 a área plantada foi ampliada em 10,3\%, diferindo da produção que teve uma retração de 4,45\%. Se comparado ao ano de 1997/1998, enquanto a área plantada foi reduzida em média de $3,2 \%$, a produção teve um recuo de mais de $19,46 \%$.

Quadro 1: Jataí - GO - Evolução da área plantada e produção de milho, 1990-2004.

\begin{tabular}{|c|c|c|c|c|}
\hline Ano & Área Plantada (ha.) & Incremento (\%) & Produção (ton.) & Incremento (\%) \\
\hline 1990 & 25.000 & 0 & 90.000 & 0 \\
\hline 1991 & 34.000 & 36 & 163.200 & 81,33 \\
\hline 1992 & 34.000 & 0 & 173.400 & 6,25 \\
\hline 1993 & 37.500 & 10,3 & 165.600 & $-4,45$ \\
\hline 1994 & 71.500 & 90,67 & 274.050 & 83,45 \\
\hline 1995 & 45.000 & $-37,06$ & 180.000 & $-34,32$ \\
\hline 1996 & 52.022 & 15,6 & 196.674 & 9,26 \\
\hline 1997 & 85.000 & 63,4 & 375.000 & 90,68 \\
\hline 1998 & 82.242 & $-3,24$ & 302.847 & $-19,46$ \\
\hline 1999 & 107.000 & 30,1 & 382.259 & 26,22 \\
\hline 2000 & 100.529 & $-6,04$ & 357.486 & $-6,48$ \\
\hline 2001 & 90.021 & $-10,45$ & 400.585 & 12,05 \\
\hline 2002 & 94.797 & 5,3 & 388.608 & $-2,99$ \\
\hline 2003 & 108.175 & 14,11 & 540.840 & 39,17 \\
\hline 2004 & 114.374 & 5,73 & 572.995 & 5,93 \\
\hline
\end{tabular}

Fonte: http://www.sidra.ibge.gov.br.

Já do ano de 2001 para 2002 a área plantada teve um incremento de $5,3 \%$, a produção sofreu uma pequena queda próximo a $3 \%$. Tais fatos podem estar diretamente ligados à variação do regime pluviométrico, uma vez que nestes períodos, possivelmente, ocorreu alguma intempérie climática no padrão de distribuição das precipitações ao longo dos dias, que não podem ser visualizados nos gráficos de médias anuais. 
Todavia, a junção destas quatro variáveis: precipitação, recorte temporal, área plantada e produção, somam um conjunto de informações que podem ser utilizadas para se obter uma análise sobre a influência da precipitação na produção e, obviamente, buscar uma compreensão de um significado do clima no sistema produtivo. É claro que este resultado pode não ser representado sob a forma de um valor contábil, ou de forma monetária (valor em R\$ ou U\$), mas sim, sobre o significado que este produziu para cada sistema e seus grupos produtivos.

\section{Conclusões}

Entende-se haver uma importante problemática do conhecimento colocada para a geografia, a partir da discussão em tela. A questão revela-se na perspectiva de se conhecer o valor do clima diante da complexidade apresentada pela realidade da produção agrícola, no confronto dos elementos que a envolvem.

Em 1948 Cholley, num artigo publicado pelo IBGE na década de 60, já apontava as dificuldades do conhecimento da realidade pela via da pesquisa científica, que no âmbito da geografia, eram expressas na complexidade e na diversidade das combinações realizadas na superfície terrestre. (CHOLLEY, 1964).

A discussão proposta vem, assim, chamar à necessidade de reflexões profundas e profícuas sobre o valor do clima, numa dimensão que não priorize o critério quantitativo, mas busque nas diversas variáveis geográficas aplicáveis ao estudo do clima, um método capaz de expressar um valor que seja reconhecido pela sociedade como elemento integrante de um sistema que a envolve, e deve assim ser visto.

A apresentação dos dados pelos gráficos mostra a dificuldade em se obter uma resposta satisfatória à questão inicialmente colocada, o que corrobora a especificidade do valor do clima nesta abordagem.

O que pôde ser avaliado neste breve ensaio, talvez seja compatível com o pensamento de Christofoletti (1982), na discussão sobre a Nova Geografia, momento em que lembra da ' magia do número', uma maneira de dizer que a solução das questões esteve na quantificação, num determinado período da história da Geografia.

Além disso, a utilização de séries estatísticas de forma isolada, nas análises geográficas, em especial nos estudos do clima, pode mascarar a verdadeira realidade, dado a "fragilidade" dos levantamentos, o que eleva a 
necessidade de reflexões bem consubstanciadas do ponto de vista qualitativo, bem como da demonstração/análise dos aspectos empíricos da pesquisa, das informações conseguidas in loco, como as fontes primárias (resultados de entrevistas no campo, por exemplo).

Contudo, considera-se que a Geografia, através de suas diversas formas de análise, pode sem dúvida, contribuir no processo de discussão que culmine na elaboração de uma teoria capaz de entender os fenômenos climáticos naturais, possibilitando a construção de uma "Geografia do Clima" onde o a relação homem/meio seja compreendida na sua totalidade.

\section{Referências}

ANA - Agência Nacional das Águas. Dados pluviométicos mensais de 1990-2004. Disponível em: http://hidroweb.ana.gov.br. Acesso em: 12/03/2009.

CHOLLEY, A. Observações sôbre alguns pontos de vista geográficos. Boletim Geográfico. Rio de Janeiro, v. XXII, n. 180, mai./jun. 1964.

CHRISTOFOLETTI, Antonio (Org.). Perspectivas da Geografia. São Paulo: DIFEL, 1982.

IBGE. Dados gerais brutos de produção de milho por município de 1990-2004. Disponível em: http://www.sidra.ibge.gov.br/dba/pesquisas/pam/default.asp Acesso em: 12/03/2009.

IBGE. Divisão regional do Brasil em mesorregiões e microrregiões geográficas. v. 1. Rio de Janeiro: IBGE, 1990. 137 p.

MORAES, Antonio Carlos Robert. Epistemologia e Geografia. Orientação. São Paulo, v. 6, p. 75-79, 1985.

SANT’ANNA NETO, João Lima. Por uma Geografia do Clima - antecedentes históricos, paradigmas contemporâneos e uma nova razão para um novo conhecimento. Terra Livre. São Paulo, n. 17, parte II, p. 49-62, 2001.

História da Climatologia no Brasil: gênese e paradigmas do clima como fenômeno geográfico. Florianópolis, SC, n. 7, maio 2004. ISSN 1519-4639.

SANTOS, Milton. Espaço e Método. São Paulo: Nobel, 1985.

SAUSSURE, Ferdinand de. Curso de Linguística Geral. 27. ed. São Paulo: Cultrix. Título original: Cours de Linguistique Générale. Paris: Payot. Tradução de Antônio Chelini; José Paulo Paes; Izidoro Blikstein, 2006.

Aristeu Geovani de Oliveira - Professor titular da Universidade Estadual de Goiás. 